Z. klin. Chem. u. klin. Biochem.

7. Jg., S. 599-600, November 1969

\title{
Photometrische Mikrobestimmung von Chlorid in tierischen Geweben
}

\author{
Von INGEBorg Kupke \\ unter technischer Assistenz von Heide-Marie Bour \\ Aus dem Institut für Klinische Biochemie und Plyysiologische Chemie der Medizinischen Hocbschule Hannover \\ (Direktor; Prof. Dr. W. Lamprecbt)
}

(Eingegangen am 9. Juli 1969)

1. Es wird eine photometrische Mikromethode zur Bestimmung von Chlorid in tierischen Geweben beschrieben.

2. Chloridwerte für Herz und Leber gesunder Ratten werden angegeben.

\section{The photometric microdeternination of cloloride in animal tissues}

1. A micromethod for the photometric determination of chloride in animal tissue is described. It is an adaptation of a previously published method for the estimation of chloride in body fluids.

2. The procedure is as follows: $5-7 \mathrm{mg}$ of dried tissue are weighed and extracted with $1 \mathrm{~m} l$ of $10 \%$ perchloric acid for 30 min. After centrifugation an aliquot of the supernatant is mixed with a ferric reagent. From 2 min. to 10 hours the samples can be measured against a blank (Filter: $\mathrm{Hg} 366 \mathrm{~nm}$, cuvette: $10 \mathrm{~mm}$ ).

3. The normal values for the chloride content of rat heart and liver are presented.

Die Elektrolyte sind auf den intra- und extrazellulären Raum in der Weise verteilt, daß u. a. Chlorid im Extrazellulärraum vorherrscht, während der Intrazellulärraum nur geringe Chlorid-Gehalte aufweist. Daraus ergibt sich für die Chloridbestimmung in Geweben, daß verhältnismäßig viel Material für die Analysen erforderlich ist.

$\mathrm{Da}$ sowohl im klinischen wie auch im biochemischexperimentellen Bereich nicht immer genügend Gewebssubstanz zur Verfügung steht (1), haben wir eine für Körperflüssigkeiten ausgearbeitete photometrische $\mathrm{Mi}$ krobestimmung von Chlorid (2) für Gewebsanalysen modifiziert.

Die Methode beruht auf der Bildung von Hexachloroferrat-[III]-komplexen in perchlorsaurem Milieu, welche bei $348 \mathrm{~nm}$ ein Absorptionșmaximum aufweisen(3).

\section{Methodik}

\section{Reagenzien}

1. $\mathrm{NaCl}-S t a n d a r d: ~ 0,4$ und $0,2 \mathrm{mVal} \mathrm{Cl}-/ / 10$ proz. Perchlorsäure.

2. 10 proz. Perchlorsäure p. a.

3. Eisenreagenz: $4 \mathrm{~g}$ Eisen-(III)-perchlorat p. a. (Fluka) in $5 \mathrm{~m} l$ dest. Wasser lösen und $500 \mathrm{~m} l 70$ proz. Perchlorsäure p. a. (Merck) hinzufügen. Lösung in brauner Flasche aufbewahren.

\section{Durchfiibrung}

Es wird das Mikrolitersystem Eppendorf benutzt. Herz- und Lebergewebe der Ratte wird $1 \mathrm{Std}$. bei $105^{\circ}$ getrocknet, anschlieBend im Mörser sehr fein pulverisiert und danach nochmals bei $105^{\circ}$ bis zur Gewichtskonstanz getrocknet. Die Proben werden im Exsikkator aufbewahrt. 5-7 mg Gewebetrockensubstanz werden in Reaktionsgefäße eingewogen. Es wird $1 \mathrm{ml} 10$ proz. Perchlorsäure (oder für Bestimmungen mit , internal standard" $1 \mathrm{ml}$ Chlorid-Standard - 0,2 mVal Cl-/l 10proz. Pcrchlorsäure) hinzugefügt.
Dic Proben werden bis zu 1 Std. im Rüttler geschüttelt, der Niederschlag wird abzentrifugiert.

Ansatz: $0,2 \mathrm{ml}$ Extrakt (oder Chlorid-Standard in 10 proz. Perchlorsäure - $0,4 \mathrm{mVal} \mathrm{Cl}-/ l$ 10proz. Perchlorsäure) $+0,2 \mathrm{~m} l$ 10 proz. Perchlorsäure $+1,5 \mathrm{~m} l$ Eisenreagenz werden gemischt. Zur Standardisierung der Methode wird das Analysenmaterial (50-70 mg) auf dem Platinnetz im Sauerstoffstrom nach ScHöNIGER (4) verascht. Die veraschte Substanz wird in $10 \mathrm{~m} /$ dest. Wasser aufgefangen. Davon werden $0,2 \mathrm{~m} / \mathrm{mit} 0,02 \mathrm{~m} / 70$ proz. $\mathrm{HClO}_{4}$ und $1,5 \mathrm{ml}$ Eisenreagenz gemischt (um vergleichbare Ergebnisse zu erhalten, werden diese Meßwerte mit einem Faktor von 0,94 multipliziert, da die Endvolumina voneinander abweichen).

Die Extinktion wird zwischen 2 Min. und $10 \mathrm{Stdn}$. gegen einen entsprechenden Blindwert gemessen (Filter: $\mathrm{Hg} 366 \mathrm{~nm}$, Halbmikroküvette Hellma Nr. 104, d = $10 \mathrm{~mm}$ ).

\section{Ergebnisse und Diskussion}

Für die Bestimmung von Elektrolyten ist die vorherige Umwandlung des organischen Materials in anorganisches zwecks Standardisier.ung unbedingte Forderung. Wir haben daher die Veraschung nach SCHÖNIGER (4) gewählt (über den Einfluß anderer Ionen u. a. m. auf die Komplexbildung und die Extinktion siehe (2)).

Wie Tabelle 1 zeigt, konnten wir mit dem Extraktionsverfahren und der Veraschung vergleichbare Resultate erzielen. Die zugesetzten, bekannten Chloridmengen konnten wir mit nahezu $100 \%$ wiederfinden. Der methodische Fehler ist in beiden Fällen annähernd gleich. Die mittels Extraktion gewonnenen Werte sind um etwa $7-8 \%$ niedriger im Vergleich zur Veraschung. Eine nochmalige Extraktion würde die Ausbeute mit Sicherheit verbessern. $\mathrm{Da}$ aber die Ergebnisse reproduzierbar sind und der Verlust nur sehr gering ist, darf man der Praxis insofern entgegenkommen, daß auf eine 2. Extraktion verzichtet wird. 
Tab. 1

Aufschluß des Gewebes durch Veraschung oder Extraktion

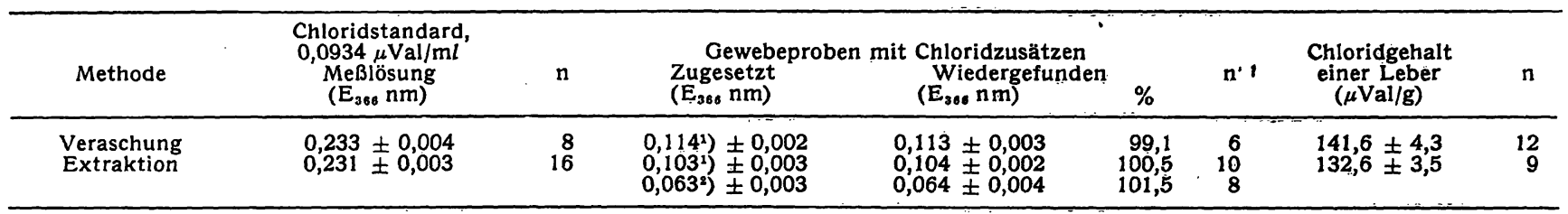

2) Leber 9) Herz

Tab. 2

Chlorid-Ausbeute nach verschiedenen Extraktionszeiten aus der gleichen Leber-Probe

\begin{tabular}{ccc}
\hline$t$ [Min. $]$ & $\mu$ Val Chlorid/g Gewebe & $n$ \\
15 & $126,7 \pm 4,0$ & 24 \\
30 & $132,6 \pm 3,5$ & 12 \\
60 & $129,6 \pm 10,6$ & 9 \\
\hline
\end{tabular}

Die Extraktion des Chlorids aus dem Gewebe geschieht rasch. Aus Tabelle 2 ist ersichtlich, daß der Hauptanteil bereits nach $15 \mathrm{Min}$. in die verdünnte Perchlorsäure diffundiert ist. Nach $30 \mathrm{Min}$. ist nur noch eine geringe Ausbeutesteigerung $\mathrm{zu}$ verzeichnen.

Die Reproduzierbarkeit der Ergebnisse wird durch folgende Werte charakterisiert:Herzmuskel: $140 \pm 2 \mu \mathrm{Val}$ $\mathrm{Cl}^{-} / \mathrm{g}$ Trockensubstanz $(\mathrm{n}=10)$; Leber: $136 \pm 1 \mu \mathrm{Val}$ $\mathrm{Cl}^{-} / \mathrm{g}$ Trockensubstanz $(\mathrm{n}=10)$.
An gesunden Ratten konnten folgende Werte ermittelt werden:

Herzmuskel: $\quad 142 \pm 15 \mu \mathrm{Val} \quad \mathrm{Cl}^{-} / \mathrm{g}$ Trockensubstanz ( $\mathrm{n}=12$ ); Leber: $142 \pm 11 \mu \mathrm{Val} \mathrm{Cl}^{-} / \mathrm{g}$ Trockensubstanz $(\mathrm{n}=20)$.

Wir schlagen folgende vereinfachte Methode zur Chloridbestimmung im Gewebe vor:

5-7 mg Gewebetrockensubstanz mit $1 \mathrm{ml} 10$ proz. Perchlorsäure 30 Min. lang im Rüttler extrahieren, den Niederschlag abzentrifugieren. Vom Überstand werden $0,2 \mathrm{~m} l$ mit $1,5 \mathrm{~m} l$ "Gebrauchslösung “ (100 $\mathrm{m} l 10$ proz. Perchlorsäure und $750 \mathrm{ml}$ Eisenreagenz mischen) versetzt. Filter: Hg $366 \mathrm{~nm}$; Halbmikroküvette (Hellma Nr. 104); $d=10 \mathrm{~mm}$.

Für einen Blindwert wird anstelle des Extraktes 10proz. Perchlorsäure verwendet.

\section{Literatur}

1. KUPKE, I., „Elektrolytkonzentrationen im Herzmuskel nach Unterbindung einer Coronararterie", Diplom-Arbeit HumboldtUniversität, Berlin und Deutsche Akademie der Wissenschaften, Berlin, 1958. - 2. Kupke, I., diese Z. 7, 221 (1969) und in Vor- bereitung. - 3. West, Ph. und H. Colx, Analyt. Chem. 28, 1834 (1956). - 4. SchöNIGER, W., Microchim. Acta 1955, S. 123; 1956, S. 869. - Kalberer, F. und J. Rutschmann, Helv. Chim. Acta XLIV, 1956 (1961).
Dr. Ingeborg Kupke z. Z. Huntington Memorial Hospital Pasadena/Cf. 91105 


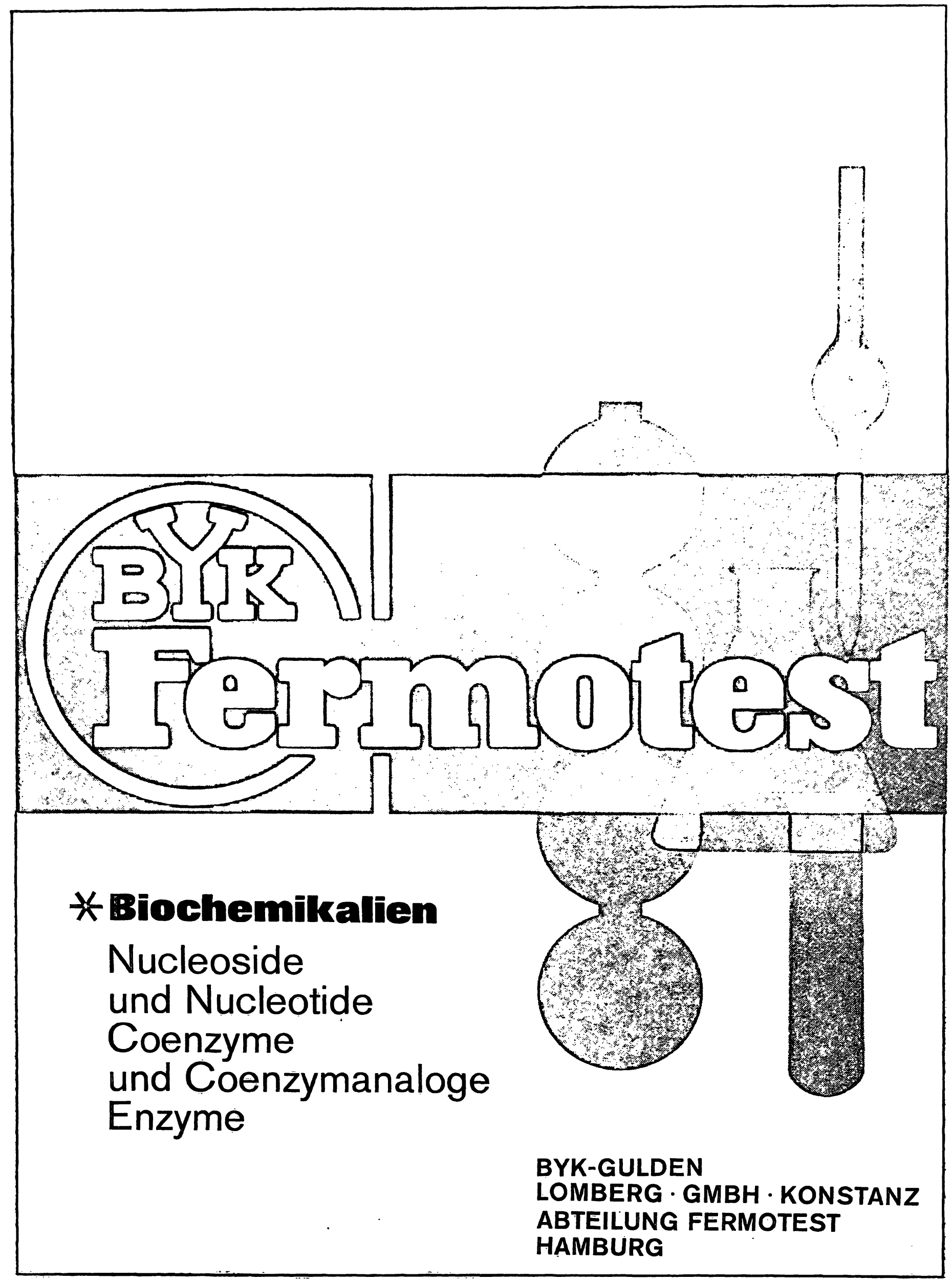


Wir suchen sofort für das im grünen. Bezirk Berlins Zehlendorf - gelegene Städt. Behring-Krankenhaus eine dynamische Persönlichkeit als

\section{Leiter des Zentrallaboratoriums}

Er soll entweder Facharzt für Laboratoriumsdiagnostik oder Klinischer Chemiker oder Biochemiker sein und neben abgeschlossener Ausbildung hinreichende Erfahrung für die Leitung des modern ausgestatteten und gut durchorganisierten chemischen Zentrallabors haben.

Bewerber, die zum Dr. chem. oder rer. nat. promoviert haben oder habilitiert sind, werden bevorzugt.

Gehalt nach Vgr. Ib BAT (ab 1970: BesGr. A 15).

Westdeutsche Bewerber erhalten vom Arbeitsamt

Anreisekosten - Familienheimfahrten

Überbrückungsgeld - Umzugskosten

und Berlin-Vorteile

Lohnsteverermäßigung

- Familiengründungsdarlehen (3.000 DM)

Berlin-Zulage

- Einrichtungsdarlehen (bis zu 10.000 DM)

Bewerbungen sind mit den üblichen Unterlagen unter Angabe der Kennziffer 495 innerhalb von drei Wochen nach Veröffentlichung an das

Bezirksamt Zehlendorf von Berlin Abt. Personal und Verwaltung - PA 1 -

1 Berlin 37

Kirchstraße 1-3

zu richten.

\section{KNAUER}

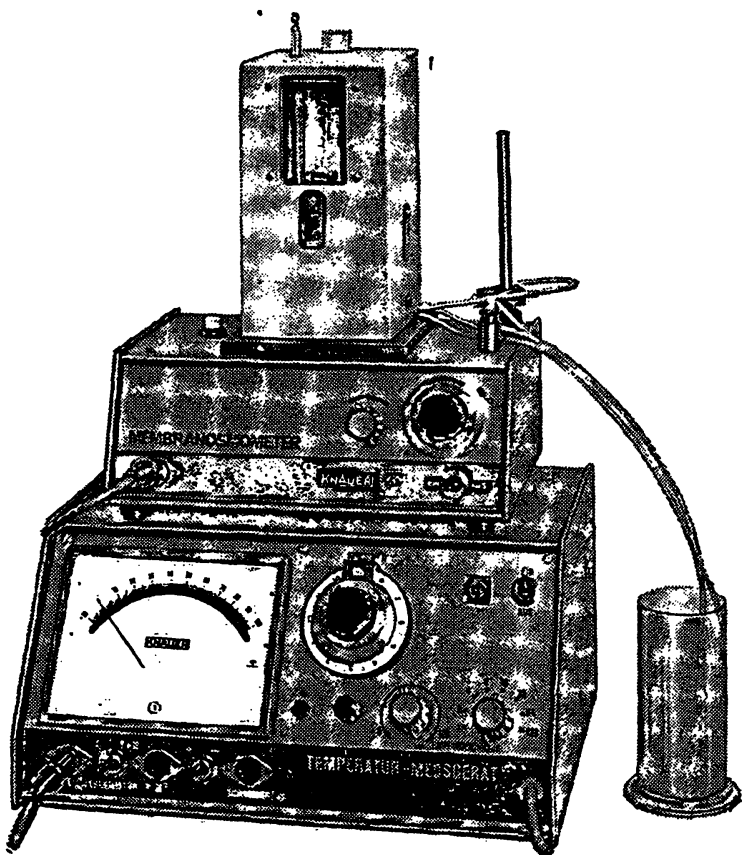

Elektronisches MEMBRAN-OSMOMETER

schnellmessend, zur Bestimmung des kolloidosmotischen Druckes und Molekulargewichten zwischen 10000 und 1000000 , zweiteilig, komplett DM 7590,- + Mehrwertsteuer

KG Dr. H. KNAUER, 1 Berlin 37 (West)

Holstweg 18, Telefon (0311) 848705

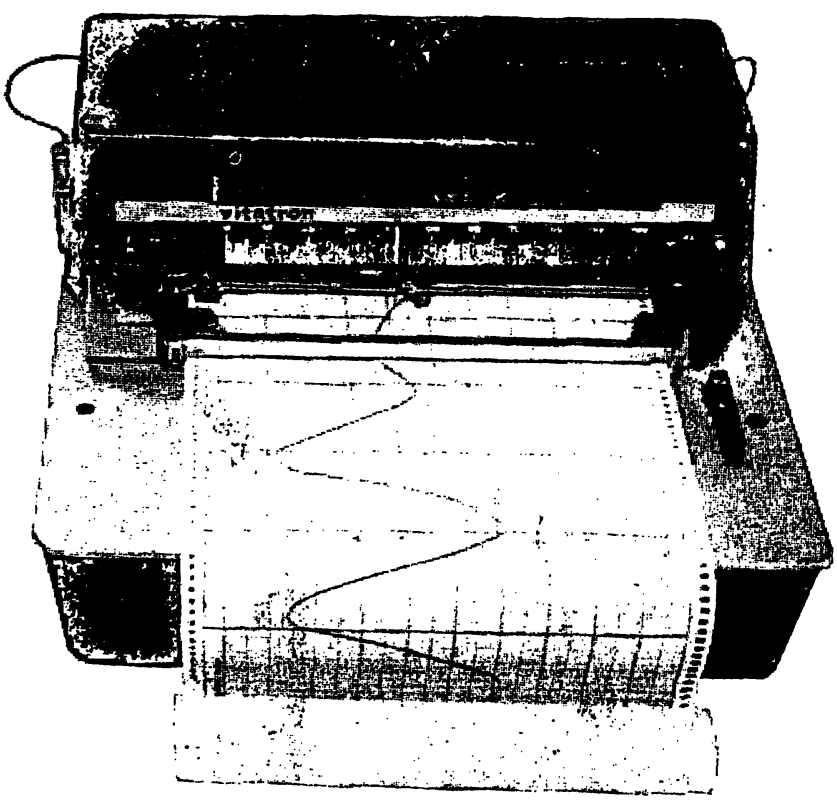

Das abgebildete Gerät kostet als LIN-Schreiber DM I995,- plus Mehrwertsteuer, in LIN/ LOG-Form DM 28I5,- plus Mehrwertsteuer.

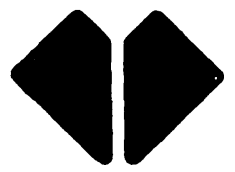

Wir sind sicher:

\section{VITATRON \\ FLACHBLATTSCHREIBER}

mit 8 Papiergeschwindigkeiten gehören zu den preiswertesten, die Sie bekommen können.

Den LIN-Schreiber mit Integrationsvorrichtung liefern wir für DM 3425,- - plus Mehrwertsteuer und den LIN/LOG-Schreiber mit Integrator für DM 4215,- plus Mehrwertsteuer. Bei diesen Preisen lohnt es sich einfach nicht, sich mit Schreiberproblemen herumzuschlagen. Lassen Sie sich die Geräte in Ihrem Hause von unseren Mitarbeitern vorführen! Denn alle Vorteile und Möglichkeiten können wir hier nicht aufzählen. Gern senden wir Ihnen vorab auch nähere Informationen.

Unsere Service-Station ist in Ihrer Nähe. 